\title{
Contemporary Challenges to the Sustainable Development of Tourism in the National Resorts of Bulgaria
}

\author{
Dessislava Alexova ${ }^{1 *}$, Elena Alexandrova ${ }^{1}$, Maria Vodenska $^{1}$, and Nikolina Popova ${ }^{1}$ \\ ${ }^{1}$ International Business School, 2140 Botevgrad, Bulgaria
}

\begin{abstract}
The survey includes a study of the potential for sustainable tourist development of national resorts in Bulgaria and the opportunities for destination management. The main accents are focused on their stages of development, mistakes made in the planning and regulations and setting guidelines for their sustainable development, in accordance with current trends. Consideration has been given to the analysis and evaluation of tourism potential which are represented as subsystems of the territorial recreation and tourism system. A study of the interconnections between them, the definition of strategic priorities and the proposals for a sustainable tourism development at a local level was carried out. It has been proven that successful sustainable tourism development in the national resorts is related to conducting systematic marketing studies, effective tourism planning and monitoring.
\end{abstract}

\section{Introduction}

The construction and development of national resorts is directly related to their resource supply, the capacity of the territory and the quality of the tourist product. Bulgaria has had experience in the construction of resorts since the late 50s of the twentieth century, which are being developed as state structures, subsidized by the state budget, and are intended for domestic and partly international tourism. This requires, when considering the problems of construction and development of resorts, to take into account some modern trends, namely: the close link between tourism and leisure; along with the chosen main form of rest, the tourist is looking for more and more additional tourist services, emotions, an experience and fruitfulness of the stay; quality of the offered tourist products and services; compliance with the rule of "minimum resources - maximum effect"; multifunctional year-round use of the material base for tourism; increased environmental requirements; change in the tourist flow - from the mass tourist to the individual tourist; search and supply of a specific tourist product, which defines the brand of the tourist site or destination. Tourism is increasingly characterized by concentration and centralization of capital. This trend leads to the dependence, on the part of small service providers, in the event of bankruptcy by a large corporation. Typical examples are the bankruptcy of Thomas Cook and the numerous cancelled charter flights in connection with the pandemic situation in 2020.

* Corresponding author: desi alexova@abv.bg 
The aim of the study is to conduct an in-depth analysis of the development of tourism in national resorts and to determine practical guidelines for their sustainable development, which will contribute to improving the competitiveness of Bulgaria as a tourist destination on the European and world tourism market. The object of the study are the resorts of national importance in Bulgaria. The nine resorts cover a small part of the territory of Bulgaria but concentrate a large volume of tourist activities in the country. According to data from the National Statistical Institute (2020), 44\% (150,000) of all beds in the country and $47 \%$ of all overnight stays registered by Bulgarian and international tourists are concentrated in them. The relative share of visitors in them is $30 \%$ of those in the country, of which $46 \%$ are foreign visitors. During the limited period of their annual operation, they generate $50 \%$ of all revenues from overnight stays in Bulgaria. The subject of research is their sustainable development in the context of modern challenges facing tourism.

The topic is relevant in terms of their sustainable development in the context of tourism as an economic sector of priority importance for the national economy in a global health, economic and financial crisis.

\section{Factors and prerequisites influencing the sustainable development of the national resorts in Bulgaria}

The present study examines and analyses the macroeconomic framework and the factors influencing the development of tourism in national resorts. The main emphasis is on the positive and negative political, economic, socio-cultural and environmental impacts of tourism, some trends in the development of the sector and consumer behavior. Some of the conclusions reached are based on the results of a study on the topic of "Development and Approbation of a Model for Monitoring and Evaluation of Sustainable Development of Tourism in Bulgaria (in the municipality of Samokov and resort "Borovets" and in the municipality of Dobrich and resort "Albena")"- a sociological research within the project "Development and Use of a Model for Monitoring and Evaluation of Sustainable Development of Tourism in Bulgaria ", financed by Science research fund, contract № КП06-H25 / 3 from 13.12.2018 .

Sustainable tourism in national resorts is associated with strategic planning - efforts to implement a "personal", specific tourist product through the use of tourist resources, according to the capacity and specifics of the territory. The product must be consistent with the diversity and complexity of tourist behavior, which is very much related to the quality of the offered services and goods. [1]

The development of tourism largely depends on the involvement of the public sector, as this business is predominantly integrated with other public services. The presence or absence of projects supporting the tourist infrastructure in a certain area is essential for the accessibility and competitiveness of tourism, so the policy of municipal authorities and their attitude to the problems of the sector are among the key factors for the development of a tourist destination. [2]

It is important that The National tourism policy and local municipal policies include emphasis on promoting entrepreneurship, public-private partnerships, overcoming the difficulties associated with stagnation after the state of emergency, the shortage of skilled labour in the service and management of hotels and restaurants, as well as to take measures to increase the level of training of highly qualified personnel. Sectoral education and the professional qualifications of workers has to take into consideration the market trends and the new market development priorities. This issue is related to the problem of difficult retention of staff and the policy of owners and professional organizations aimed at motivating executive and managerial staff. [1] 
In tourism, health care and the need for security are increasingly being felt. Tourists avoid destinations that are considered dangerous. Current trends show that the cost of security will increase significantly, and the industry will need to be better prepared and more flexible when meeting tourism demand in times of crisis. Terrorist acts, regional wars, pandemics, global pollution and other global crises have unfortunately become part of everyday life. In tourism, this increases the need for security and tourists avoid destinations that are considered dangerous. Security costs will increase significantly, and the industry will need to be better prepared to meet tourism demand more flexibly in times of crisis, especially during a pandemic. The selection of a destination will also include significant factors such as the quality of drinking water and environmental pollution and adequate measures against COVID-19.

The well-being and standard of living of the population have a significant impact on the consumption of tourist services. This influence will affect the personal needs and perceptions of tourists. There is a tendency to increase interest in smaller accommodation. The trend "back to nature" will lead to simpler means of accommodation - from hotels to bungalows, from caravans to tents. Service providers that manage to create entirely new products and implement innovations will be successful on the market, and the product of hobby tourism will develop at an accelerated pace. Destinations will increasingly benefit from easy and cheap access, especially if they advertise events organized outside the active season. Increased accessibility will stimulate the demand for short vacations abroad and migration from large cities to smaller and quieter resorts and rural areas.

The economic importance of international tourism is even more pronounced in terms of the ratio of income in national resorts from Bulgarian and foreign tourists. The large resorts of Sunny Beach and Golden Sands, followed by Albena, rely almost entirely on foreign tourists, while in winter resorts the difference is not so drastic. Only in the resorts of Borovets and Pamporovo, although with a slight predominance, the ratio is in favor of domestic tourism, and this trend has been constant over the past 5 years. The crisis around COVID-19 has led to the introduction of additional conditions and changes in the contracts of insurance companies with tour operators and accommodation providers.

Social and cultural changes, along with the demographic crisis, determine a new motivation for travelers. Today, tourists plan their trips, and their goal is to get to know as many places as possible in a short time with the shortest possible stay, with an emphasis on the experience. Consumers easily change their preferences and requirements, search for increasingly profiled products and detailed and reliable information about them through independent research on the Internet. Before the final purchase decision, they compare the characteristics and prices of several tourist offers and increasingly look for opportunities for social and cultural interactions with representatives of the host community. [2]

Tourists are becoming more demanding and confident in their needs and rights. It will reduce loyalty to certain destinations, and those who do not meet the standards will lose customers for a long time. Regions that offer a diverse product will be preferred. The experience and critical attitude will encourage tourists to visit again destinations they were happy with in the past, and the product will be diverse. More experienced tourists will be more critical of the authenticity of the places they visit as part of their need for an emotional experience.

Over time, health has become essential and it influences the decision for a holiday. Destinations that are not considered environmentally friendly will gradually be avoided by tourists. The demand for sea recreational tourism will decrease, while the demand for active vacations will increase, and this will form the need to build suitable facilities for active sports. Demand for beauty and health products will increase (including mineral pools and spa and fitness centres). 
There is a tendency for the number of elderly people to increase progressively. They will be healthier and have more income than in the past. In this sense, the number of experienced tourists will grow at a much faster pace than tourism development, which will increase the requirements for quality, comfort and security of accommodation and transport, will increase the demand for more diverse and quality additional tourism services corresponding to the modern level of offer. More sought after will be individual programs that take place outside the busy season and include relaxing entertainment opportunities.

A study by Dogramadzhieva and Terziyska (2020) on the impact of COVID-19 on the travel attitudes of Bulgarians shows an increased importance of official bans and recommendations for older respondents, while the weight of general uncertainty about the future and financial difficulties are featured in the answers in the survey by younger participants. The fear of infection / disease is more pronounced in respondents up to 45 years of age and weakens with age. From this it can be concluded that consumer attitudes of the elderly when traveling will not change significantly with regard to domestic tourism in Bulgaria. Younger consumers of tourist services would be more worried, respectively more demanding in terms of those elements of the offer that are relevant to ensuring safety - a fact that should be taken into account when formulating tourist offers for Bulgarians by business enterprises. Some tourists will focus on a smaller number, shorter and closer to closer destinations trips with a smaller budget and increased attention to hygiene and safety, but a significant part of people do not intend to change their usual behavior when traveling. [3]

The main differentiated problems, according to the results of a study on "Development and testing of a model for monitoring and evaluation of sustainable tourism development in Bulgaria (in the municipality of Samokov and Borovets resort and in the municipality of Dobrich and Albena resort)" - sociological research within the project "Development and testing of a model for monitoring and evaluation of sustainable development of tourism in Bulgaria (on the example of national resorts)" are: the quality of tourist services in the sites of owners - foreign to the industry and to professionalism, non-compliance with the standards, norms and ethics of business, with which they damage the image of the whole destination, chronic shortage of qualified tourist staff due to low pay, short seasonal employment and unfavorable working conditions in some sites.

The negative effect of redevelopment has different dimensions: changed atmosphere; impaired aesthetics; congestion of tourist resources - beach and forest resources are not inexhaustible, and the reckless exploitation of sand dunes and forests can lead to their disappearance; congestion of the tourist and engineering infrastructures and imbalance between them and the means of accommodation, the most acutely noticeable being the failures in the sewage system in the middle of the summer season; broken and difficult complex relations, functions and organization, etc. Unacceptable discomfort and difficulties are created by the failures of power supply and drinking water regimes. The electricity, water and sewerage systems are designed to perform their functions at a load many times exceeded by the redevelopment. [4]

The road network in the resorts is congested with tourists. Additional difficulties are brought by the street trade sites, reducing their capacity, and the uncontrolled design and implementation of the new tourist sites for construction and reconstruction often goes beyond the legal framework of the adjacent terrains and occupies parts of natural resources and common parts of the complex. In this way, resource areas and volumes of the water area, beaches, dunes, parks, green areas and common complex parts are lost and destroyed irretrievably. The climatic elements in the complexes are deteriorating, as a result of the complete covering of their territory with concrete and asphalt, which cannot be compensated by other means. [4]

Climate change and the constant pressure on the environment from the other economic sectors have an impact on tourism. Problems with water supply, the presence of solid waste 
outside landfills, deteriorating air quality, increased traffic, dust and noise pollution, have a strong impact on environmental components and lead to serious environmental problems that either threaten the tourism product itself, or reach a larger scale and affect the image of the whole area. [5]

Pollution of natural tourist resources and the environment is an environmental problem and a secondary effect of redevelopment, which is caused directly and indirectly. The use of natural resources and anthropogenic pressure by too many visitors leads to environmental pollution and change in their condition. As a result, in many of the congested tourist places, the ecosystem is undergoing permanent and irreversible changes in its physical and chemical composition, as well as the flora and fauna inhabiting it. The indirect way of pollution is through wastewater systems. The multiple increase of the accommodation base and the number of tourists significantly exceeds the ability of the wastewater stations to function fully and the untreated wastewater flowing into the sea brings a large number of pollutants. Very often, the chemical and biological indicators - nitrogen, phosphorus and E. Coli bacteria, reflecting the presence of untreated wastewater, cover health standards, but do not meet the recommended levels, providing good comfort. There are regular cases in the active summer months of canal accidents, in which the alleys of the complexes are filled with their raw content in all complexes on the Black Sea coast. [4]

The incessant construction works and the excessive traffic in the resort complexes cause noise and dust pollution. The most common problems that are mentioned are: progressive increase of car traffic and risk of air pollution in the municipality where the resort is located; air dust in urban areas; high degree of spatial concentration of tourist production sites in close proximity to unique natural and cultural resources (beaches, architectural and archaeological monuments).

Among the main threats related to environmental pollution are also: pollution of agricultural land with household and construction waste from intensive construction in the resorts of Sunny Beach, Golden Sands and St. St. Constantine and Helena, exceeding the bearing capacity of the beaches and the danger of activation of landslides, as well as problematic management of the sea beaches by the state by giving them to private companies on concession. Serious threats are the redevelopment of parts of the coast, causing a negative effect on the environment, the danger of pollution of coastal bathing waters from passing large cargo vessels, the danger of natural disasters (landslides and erosion processes, violent waves, etc.) on the overall tourist activity in coastal areas.

The last decades have been a period of digitalization and intensive introduction of electronic technologies in social processes. The development of technological factors on a digital basis have been changing the volume and structure of tourist demand and consumption. Digital information technologies are constantly opening new opportunities for innovation in the tourism industry - introducing robotics in elements of tourism services, electronic channels for communication and distribution of tourism products etc. The requirements for increasing the hygiene and safety of tourists in Covid-19 conditions require additional implementation of new technologies and robotics, as in the hotel business (checkin by vending machine, implementation of automated information systems in various hotel services, etc.), catering, tour operator and agency activities, as well as service providers accompanying tourist trips. New information and communication technologies allow small businesses in the industry and underdeveloped tourist areas to promote and enter markets at relatively low cost, on a par with established tourist destinations, and hotels that innovate are proven to be more competitive in an extremely dynamically changing environment.

\section{Mechanisms for sustainable development of tourism in Bulgarian resorts}


In the so formed large, urbanized territories extremely often, there are serious contradictions between the needs of the resort activity from territories and the development of the traditional economic branches. The main requirement for them is the protection of the available natural resources and ensuring the necessary ecological conditions for conducting resort activities. In the design, construction and operation of resorts and resort construction, it is generally accepted that the structure of the resort areas includes appropriate use, protection of land of the different owners and construction in accordance with their main purpose - development of resort functions on the basis of the use of natural resources. When designing the resorts, it is necessary to have complete information about the available resort resources and a program for their development and use, on the basis of which to determine the manner of construction and the construction of the specific resort area. This also applies to determining the location of new resorts. It is important to assess in advance the need to open a new resort or expand an existing one, including social and economic feasibility and efficiency, taking into account: the needs for resort treatment and recreation, the prospects for international tourism and resort needs in this regard, the number and capacity of the existing resorts and to what extent they satisfy (quantitatively and qualitatively) the indicated needs. In the case of resorts that are an integral part of separate resort areas, it is necessary to use the analyses and assessments in the pre-designed development schemes of the resort areas. This requirement is necessary because it indicates the use, structuring and construction of the respective resort areas, which should correspond to the long-term and socially recognized goals of resort activity development in the most effective use of the resort potential and environmental protection. [6]

The expansion and modernization of the functioning national resorts is related to the improvement of the structure and construction of their territory, reconstruction of the existing material base, improvement of the sanitary and hygienic condition, restoration of the natural environment, etc. Their reconstruction must lead to more efficient use of natural resources, reflecting the growing demands of modern tourists to the recreational environment. It is necessary to observe (where possible) the historically established structure of the resort areas and the nature of their construction. The development plan of the resort territory must include the solution of the following main problems: improvement of the structure of the territory, regulation of its perspective development, rational use of the available tourist resources; improvement of engineering infrastructure and service; ecological and landscape measures for landscaping; complex assessment of the resource provision, use and protection of the tourist resources; assessment of the existing construction, the structure of the territory and the accepted structure of the resort; analysis of the material base and the engineering equipment on the territory of the resort; social and economic evaluation, etc. It is of paramount importance that the construction of new accommodation, restaurants and attractions can be carried out by permissible compaction of the developed territory, construction of a new base on the site of non-compliant sites and construction of sites in the peripheral parts of the resort, but within the area of its influence. Another important aspect in the planning and development of resorts is that their development schemes include functional zoning, which will allow the proper use of different structures, depending on the capabilities of the existing territory, its traditional development, its degree of construction, its specific nature, etc. The functional zones (real, residential, economic and green areas) can be clearly expressed and separated independently in the resort territories or some of them can be solved in a more differentiated way. [6]

Reconstruction of the transport network in the existing resorts must be carried out primarily in order to comply with sanitary and hygienic requirements: removal of existing highways and transit roads outside the resort; introduction of a regime for use of the existing road transport network; organizing, if possible, special resort transport; creation of a system of pedestrian transport connections, connecting all zones of the resort, delineation of 
pedestrian zones, etc. In this way, existing road conflicts can be eliminated, noise and dust pollution can be reduced, traffic can be eased, and transport and pedestrian routes can be safely separated as well as. The system of pedestrian connections in the resorts should be isolated from the transport roads, but with convenient connections to them and the possibility of using public transport. Vertical transport communications in mountain resorts are the different types of lift roads, for the construction of which, their equipment and use there are a number of requirements that need to be met. [6]

The introduction of innovations and new technologies will contribute to improving the quality of the product, with lower consumption of energy, materials and live labour. The application of complex automation in tourist sites is aimed at facilitating the service staff and improving the efficiency of tourist services and can also be related to ensuring the safety of tourists. An example can be given with the devices that measure the body temperature of the visitors upon entering the tourist site and the mechanization of the process to ensure better sanitary and hygienic conditions. There is a need for full mobilization of interested parties to adapt to the ever-growing needs of visitors in this direction, more full and extensive use of all available opportunities of economic potential to fully provide the necessary resources. The process is difficult and requires qualified and trained staff to ensure good organization, order and discipline in the sites entrusted to them, to show creative thinking, creativity and initiative towards modern technologies to offer a variety of services and improve the quality of tourist services.

It should not be forgotten that tourism is an industry of hospitality and to underestimate the service in tourist sites, which for years is not competitive even with that in our neighboring countries Greece and Turkey. The training of qualified staff to be good representatives of Bulgarian hospitality and to leave lasting positive impressions on tourists is a way to support the quality of service and competitiveness of our resorts within international tourism. Customer care and building a quality hospitality industry should also be the result of a targeted tourism policy.

\section{Threats to the sustainable development of Bulgarian resorts}

Good governance at all levels requires compliance with the law. A very small percentage of investors, who have funds know what they want and achieve their goals more often with disrespect and non-compliance with the law. A large number of hotels and restaurants in national resorts remain illegal. A fact is the gross violation of the requirements of construction and the construction of resorts. The important point that all hotels are open to the sea is being neglected. The construction of high hotel complexes on the first line of the beach, caused great damage to the general appearance of the seaside resorts and creates conditions for complaints from tourists. An additional negative impact is exerted by the destruction of green and sandy areas, flower and forest plantations, non-compliance with the capabilities of water supply, sewerage and other facilities in the resorts.

A threat to the sustainable development of tourism is the emerging economic crisis, which is associated with rising unemployment, mass bankruptcies among the tourism business and an increase in the grey sector in tourism. The lack of reliable statistical information is an additional limiting factor for the preparation of qualitative analyses and forecasts in the tourism sector. The Unified Tourist Information System (UIS) is expected to compensate to some extent this problem, but in order to establish clarity regarding the subjects of the tourist market, current and subsequent control over the tourist activities, tourist sites and the quality of the tourist product, it is necessary to establish an effective control body. The problem with the qualification of staff also tends to worsen. This necessitates the introduction of criteria and evaluations of work, following successful global practices in established tourist destinations, including the introduction of licenses, certificates, master certificates and more. 
The development and establishment of tourism as a priority sector of the national economy requires the application of a new economic model based on the following basic principles: ensuring equal participation of all forms of ownership in the tourism industry; state economic regulation and stimulation of tourism; involvement of a wide range of interested parties in the development of tourism, application of experience from other industries abroad and good world practices; preparation of a market-oriented and economically justified organizational and management structure; creating a new quality and complex structure of the tourist product. The current tourism policy should be completely rethought, in accordance with the changes after COVID-19, and it is important to emphasize the safety of tourists, environmental, hygiene and health requirements in the resorts. The priority development of domestic tourism requires systematic and coordinated efforts, both at a national and a local level, to minimize the negative impacts associated with the redevelopment of the Black Sea coast, the shortage of qualified personnel and the prevailing poor quality of the tourist product. The efforts of the Ministry of Tourism should also be aimed at attracting elderly tourists and developing social and health tourism.

\section{Conclusion}

Sustainable development of tourism in national resorts requires targeted and constant efforts, both by local authorities, in partnership with other interested parties and, at a national level, by pursuing a coherent government policy, which includes on the one hand a clear strategic and legislative framework and, on the other hand, a well-targeted marketing and advertising policy in line with modern trends in tourism demand and dynamically changing consumer behavior. The implementation of a centralized management system and the monitoring of sustainable development guarantee better management of the complexes. Thus, in the context of sustainable development, the maximum parameters of organizational, economic and social efficiency can be achieved.

It is essential to develop the product policy in connection with the opportunities for offering specialized types of tourism, according to the characteristics and tourist potential of the region. The emphasis on local natural resources and cultural identity is key to defining a positive image and development of a tourist brand of national resorts. To this end, it is necessary to carry out in-depth research, constant monitoring and periodic updating, in accordance with the dynamically changing realities. In this way the traditional tourist package will be enriched with new elements and a complex tourist product will be able to be formed, which, in turn will lead to an increase in the quality and image of the national resorts. Sustainable utilization of the tourist potential, which largely remains untapped, will lead to a decrease in seasonality in Bulgarian resorts and an increase in economic profitability.

All this requires serious efforts and perseverance, as the problems with redevelopment, destruction of natural resources continue and affect the reduction of the competitiveness of Bulgarian resorts. Among the long-standing weaknesses remain sluggish and unaddressed advertising at national and local level, poor infrastructure, underestimated cultural heritage, unrealized wealth of healing mineral waters, lack of well-trained staff, which reflects the culture of service in all industries and even in food quality.

This publication is financed by Science research fund through project "Development and use of a model for monitoring and evaluation of the sustainable development of tourism in Bulgaria”, contract № КП06-H25/3 from 13.12.2018.

\section{References}


1. D. Alexova, Y. Yordanov, Business planning as a tool for regional development of tourism on the example of Smolyan district, In: Proceedings of the XI International Scientific Conference "Intelligent Specialization in Bulgaria". Bulgaria in the European Union - benefits and challenges. Sofia, IBS, 907-921 (2014)

2. D. Alexova, Model for sustainable development of a forming tourist destination on the example of the Botevgrad Municipality, (Sofia. IBS, 2019)

3. E. Dogramadzhieva, I. Terziyska, Influence of COVID-19 on the travel attitudes of Bulgarians, Survey results. DOI: 10.13140 / RG.2.2.13230.95049 (2020)

4. D. Stoynov, Tourist policy of the Republic of Bulgaria for sustainable development of the resort complexes, unpubl. dissertation, University of Economics - Varna, Department of Economics and Organization of Tourism, Varna (2014)

5. M. Vodenska, Assessment of the impacts of tourism on the environment in the Bulgarian national resorts, Analytical report by the project "Development and use of a model for monitoring and evaluation of the sustainable development of tourism in Bulgaria", contract № КП-06-H25/3 from 13.12.2018, financed by Science research fund (2020)

6. S. Grancharova, Resorts - problems, design, practice, (ed. Polygraphy Ltd, Plovdiv, 1994) 